\title{
Are attitudes towards bioethics entering a new era?
}

\author{
Noëlle Lenoir UNESCO's International Bioethics Committee, Paris, France
}

Since the human life process is at their roots, a legal framework without precedent for medical practice and research was bound to develop from modern biology and genetics. A vast amount of legislation has been enacted in the field of bioethics. Committees on the ethics of living sciences have blossomed. The latest of these committees was set up by President Clinton in the US. Within the United Nations, UNESCO's International Bioethics Committee (IBC) is about to approve a preliminary draft of a "Universal declaration on the human genome and human rights". This will be the first text devoted to this subject, at a universal level.

Its objective is to reaffirm and update the basic principles of the human individual's dignity, of freedom for scientific research and of solidarity between individuals and states, and to apply these principles in the context of modern biomedical sciences.

In order to uphold the principle that genetic research and applications should be conducted with respect for human rights, the UNESCO committee's declaration will define the human genome as a fundamental part of mankind's common heritage.

This definition reminds us of the links - biological and moral, as well as intellectual - which unite "all members of the human family", as stated in the 1984 Universal Declaration of Human Rights.

To ensure that these principles do not remain mere ideas, UNESCO's IBC has decided to study them at each of its annual sessions in the light of real cases. The purpose is to evaluate the difficulties in interpreting these principles and the nature of the obstacles which they could encounter in practice.

The two themes set for the October 1996 session of the IBC illustrate the committee's determination to bring its discussions as closely into line with real life as possible.

The first discussion covered "novel food" which means food produced through a genetic process. This provided an opportunity to emphasise the rights of consumers and the responsibilities that lie with those who manufacture, market and control these products.

We must take note that one of the major challenges set by modern biotechnology concerns controlling risks to health and the environment, regardless of a country's level of development. The scientific community has already demonstrated its concern over this matter of self-regulation, at Azilomar, where a historic congress in 1975 proposed a postponement for several years of the use of genetically modified organisms.

But this sort of approach is not enough. It is up to the authorities, both national and international, to guarantee the safety of its citizen-consumers. As Jacques Chirac, the French President, said in his opening speech at the Fourth Session of the IBC on 3 October 1996, bioethics are the responsibility of the world's political community. Chirac highlighted the need for "an urgent response to situations whose consequences are most often measurable only over a substantial period".

The new technological context today calls for "prudence", according to the French President. This, Chirac said, means "preparing for the worst when there are fears of irreversible damage".

In this same spirit, would it not be better to apply to genetically modified food the same control procedures used for pharmaceuticals both before and after marketing? Such a system of "vigilance" (in the same way as pharmacovigilance) would have the advantage of guaranteeing permanent monitoring of consumption of "novel food", with a built-in warning system designed for emergencies.

The second theme discussed at the IBC's October session covered medical experiments on human beings. The objective here was to uphold the patient's right both to medical care and his or her own freedom of choice. In the context of medical experiments, it has long been agreed that the patient must be fully informed and free to consent. This has been repeatedly affirmed over and over again in a number of international and national legal texts.

But can we regard agreement by a sick person, who is physically weak and morally fragile, as "free" and "fully informed"? And what can we say about children on whom these new tests might be conducted?

When we invoke this requirement of consent, should we exclude from research agreements those patients who are unable - for either legal or practical reasons - to express their desire to take part? 
And how should we judge the system of drawing lots to select which patients are to receive a genuine medicinal product and which are merely to be given a placebo? All these questions confirm that principles must constantly be confronted with real situations.

This is precisely what UNESCO's International Bioethics Committee has been seeking to achieve at each of its annual sessions. Now the time has come to evaluate the scope of this ethic of law in everydayt life: in medicine, the workplace and the family.

Noëlle Lenoir, a member of the "Conseil constitu $\stackrel{\vec{F}}{\vec{F}}$ tionnel" of France, is President of the Internationat Bioethics Committee of UNESCO and chairs the Grous of Advisers to the European Commission on the Ethicaf Implications of Biotechnology. 